Journal of the Society for the Study of Architecture in Canada

Le Journal de la Société pour l'étude de l'architecture au Canada

\title{
Treaty Lands, Global Stories: Designing an Inclusive Curriculum
}

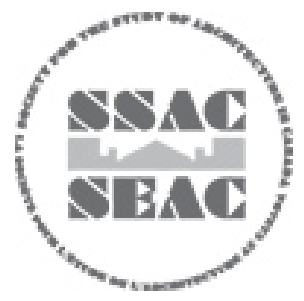

Samuel Ganton, Amina Lalor et Paniz Moayeri

Volume 43, numéro 2, 2018

URI : https://id.erudit.org/iderudit/1058036ar

DOI : https://doi.org/10.7202/1058036ar

Aller au sommaire du numéro

Éditeur(s)

SSAC-SEAC

ISSN

2563-8696 (numérique)

Découvrir la revue

Citer cet article

Ganton, S., Lalor, A. \& Moayeri, P. (2018). Treaty Lands, Global Stories:

Designing an Inclusive Curriculum. Journal of the Society for the Study of

Architecture in Canada / Le Journal de la Société pour l'étude de l'architecture au

Canada, 43(2), 15-25. https://doi.org/10.7202/1058036ar 


\section{TREATY LANDS, GLOBAL STORIES: DESIGNING AN INCLUSIVE CURRICULUM ${ }^{1}$}

SAMUEL GANTON, from Milton, Ontario, is an intern architect and a recent graduate of the Master of Architecture program at the University of Waterloo School of Architecture. His thesis, entitled Cauldron of Forces: Designing a Thunderstorm Observatory on Lake Maracaibo, focused on the experiential intersection between architecture and weather.

AMINA LALOR is a graduate student at the University of Waterloo School of Architecture. Born and raised just north of Toronto, Ontario, Amina is of Métis, Vietnamese, and Irish descent and a member of the Métis Nation of Ontario. Her thesis research investigates the creative responsibility of the designer in the process of reconciliation, decolonization, and Indigenous resurgence in Canada.

PANIZ MOAYERI is a graduate student at the University of Waterloo School of Architecture, where she also received her Bachelor of Architectural Studies in 2015. Her research looks at the connection between space and queer heritage in the Iranian LGBT refugee community of Toronto. Paniz was fifteen when her family immigrated to Toronto from Tehran.
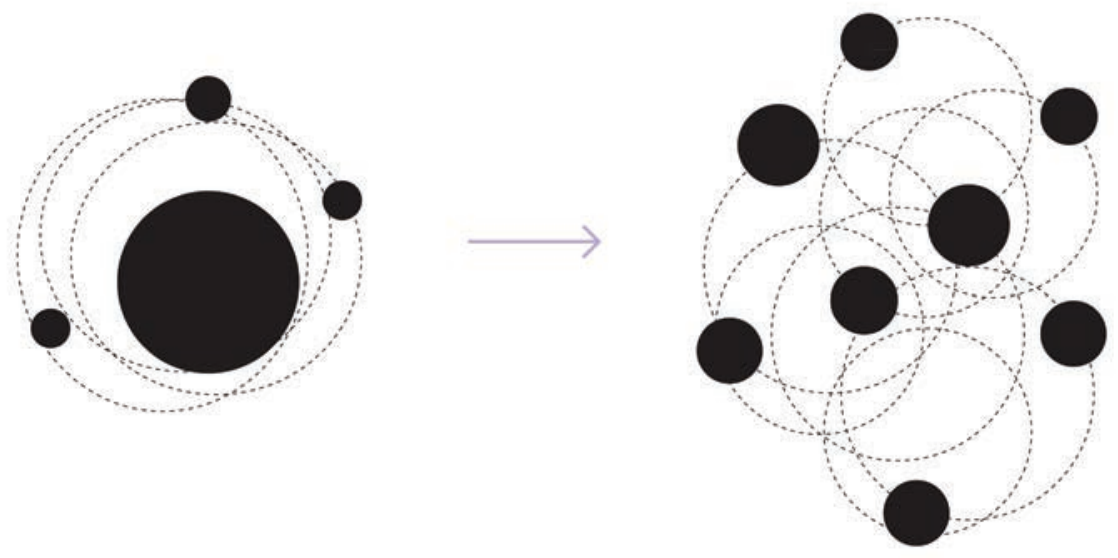

FIG. 1. A CONCEPTUAL ILLUSTRATION OF THE CURRENT MODEL OF CONTENT INCLUSION IN MANY ARCHITECTURE SCHOOL CURRICULA (LEFT) WHERE THE WESTERN CANON IS AT THE CENTRE OF EDUCATION, IN COMPARISON TO A POTENTIAL MODEL (RIGHT) WHERE CONTENT FROM DIFFERENT CULTURES AND WORLDVIEWS HOLD SIMILAR WEIGHT. | ILUUSTRATION: BY AUTHORS.

\author{
SAMUEL GANTON, \\ AMINA LALOR AND \\ PANIZ MOAYERI
}

Treaty Lands, Global Stories (TLGS) is a student-led extracurricular initiative at the University of Waterloo School of Architecture formed in the Fall of 2016 by the three graduate students who sign this article. The name speaks to the spatial, political, and cultural context within which we operate here in Canada-a context that is not adequately addressed in the Eurocentric curricula of many Canadian architecture schools. TLGS advocates for greater diversity in the University of Waterloo's architectural curriculum to reflect the Indigenous heritage of the land on which the school is situated, as well as the diversity within the school's student body.

We acknowledge that the University of Waterloo School of Architecture is situated on the Haldimand Tract, the land promised to the Six Nations that includes six miles on each side of the Grand River. We are on the traditional territory of the Neutral, the Anishinaabeg, and the Haudenosaunee peoples [https://uwaterloo.ca/faculty-association/ about/land-acknowledgement]

Let us start by stating that site is at the crux of our work as architects. We need to be aware of the land and its story, underfoot, and under-foundation. Canada, as it exists today, is the direct result of the colonization and settlement of Indigenous territories. For centuries, architecture and planning have been tools for colonization, acting to displace, marginalize, confine, and assimilate Indigenous peoples in order to expand empires and bring European settlers to the so-called "new world." The parcelling of land and the forms of our buildings arrived with colonization. We have inherited this spatial and conceptual framework that has been continually responsible for the marginalization of the "other."

Treaties were established between Indigenous peoples and the Crown as 


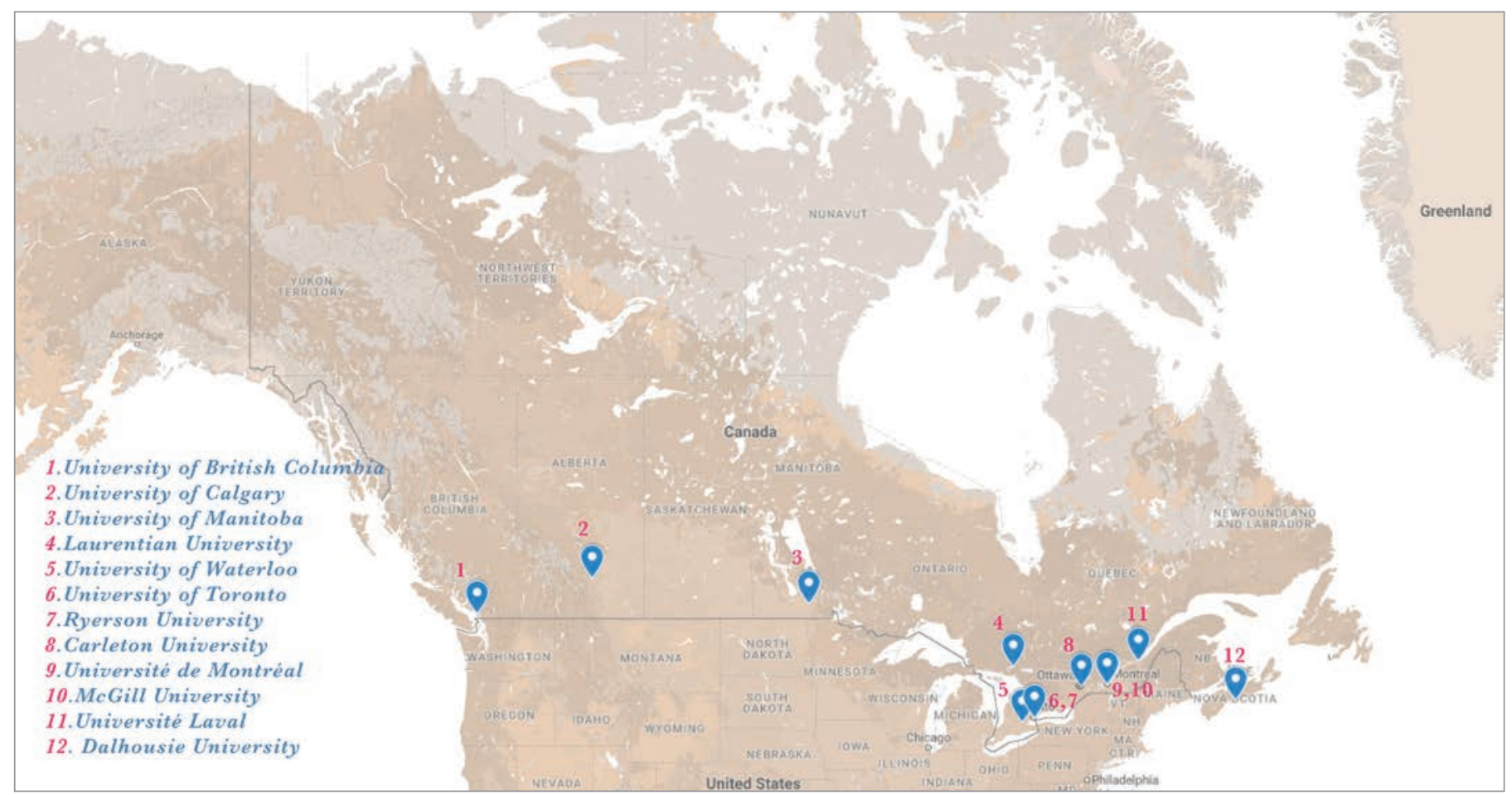

FIG. 2. CANADIAN SCHOOLS OF ARCHITECTURE LOCATED ACROSS CANADA. | BASE MAP SOURCED FROM GOOGLE MAPS, ALTERED BY AUTHORS.

agreements to share the land, for all to benefit from it. For most of us in Canada, it is because of these treaties-and their subsequent violations - that we are able to call this land home. We are all treaty people, both Indigenous peoples and settlers, historic and recent. But we forget this, or we are never taught it to begin with.

Recent immigrants enter the fold of both the treaties and settler-colonial frameworks-unknowingly-when they arrive in Canada. They, too, experience the imposition of Western values to the detriment of the cultures they carry with them. The situation is further complicated by the embedded colonial baggage that exists in the countries from which many of these individuals arrive. Since the nineteenth century, modernization and westernization have been synonymous terms in the progress of non-Western countries. Orientalism, as Edward W. Said describes it, is a by-product of colonial attitudes, whether directly inserted into colonized nations or perpetuated through Westerndominated thought. ${ }^{2}$

New arrivals to Canada, whose cultures are already greatly affected by orientalism and Western influence (if not outright colonialism), are marginalized still further.

As architects, we operate within this settler-colonial context dominated by a Eurocentric worldview. By failing to acknowledge that settler-colonialism forms an implicit frame around how we practice architecture, we are, whether consciously or not, supporting the hegemony. As architects shaping the built world, we have a social responsibility to address this context. To change the way we build, we must first change the way we learn to build. Architecture schools and their curricula must prepare students to work within and challenge the settler-colonial context.

How can our schools do this? How do we shift our perspectives and disrupt entrenched biases? How do we design an inclusive architectural curriculum? We want to grapple with these questions and we think it is imperative for all Canadian architecture schools to do the same.

As Treaty Lands, Global Stories, our work so far has encompassed three sets of investigations:

- a literature review of scholarship regarding the Western canon in architectural education,

- a survey of Canadian architecture school curricula,

- community engagement within Waterloo Architecture and beyond. 


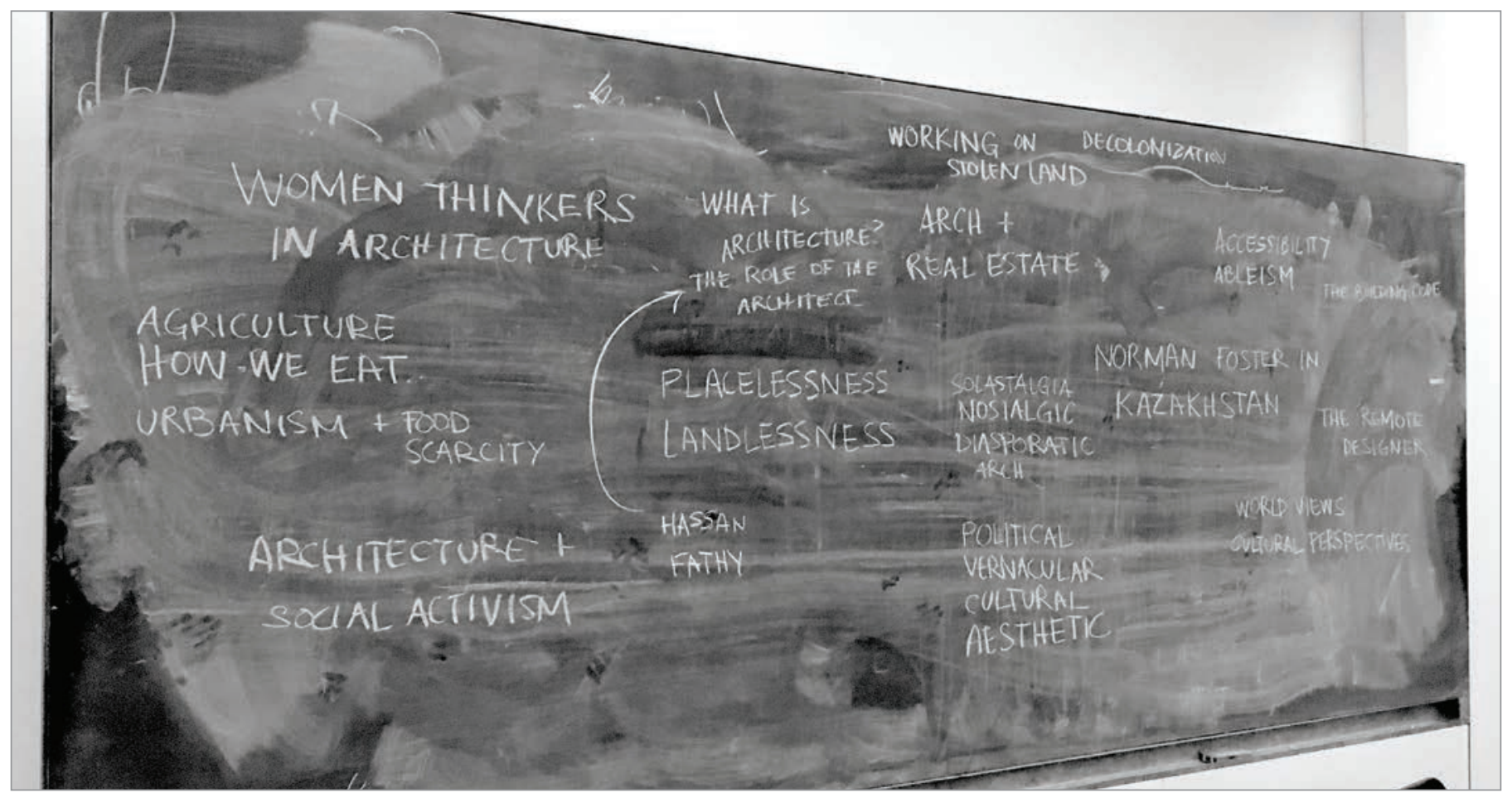

FIG. 3. COURSE TOPIC BRAINSTORMING DURING THE 'EXPANSION PACK' SYLLABI WORKSHOP. | AMINA LALOR.

The following sections provide a summary of our findings from each of the above inquiries. We view our research as a preliminary investigation, laying the groundwork for Canada-specific research and action that we, and others, may pursue. We share it here to encourage other scholars and students to continue this work of understanding and questioning the cultural pedagogy of architectural education in this country.

\section{LITERATURE REVIEW}

In our literature search, we reviewed a number of sources in order to interrogate the idea of "canon" and its framework within North American architectural education.

When we use the word "canon," we are drawing on an etymology that includes the religious concept of books which are accepted as genuine and inspired ${ }^{3}$ - the texts that preserve and enforce orthodoxy. The term "Western Canon" alludes to works of art, literature, and architecture, but also to the criteria by which they are selected and the narrative thread that ties them together. In "The Canon and the Void: Gender, Race, and Architectural History Texts," a study published in the Journal of Architectural Education (JAE) in 2006, Meltem Ö. Gürel and Kathryn H. Anthony state that "buildings encompassing the traditional boundaries of the canon reflect traditional Eurocentric patriarchal perspectives." 4 The Canon is not just content. It conveys a worldview. The Western Canon tends to be portrayed as "the big show" in architectural history, with the achievements of other cultures as sideshow acts. In her essay "Architectural History in Professional Education: Reflections on Postcolonial Challenges to the Modern Survey," Sibel
Bozdogan writes that "the Western tradition is still the primary point of reference with respect to which non-Western architectural traditions acquire significance and become eligible for inclusion." ${ }^{5}$ That is the effect of "tokenism": when a token effort is made to include marginalized voices or non-Western content, Eurocentric Western hegemony is left unquestioned and undisturbed.

Architectural history, taught through the canonical lens, often frames the development of European architecture in isolation from other cultures and the rest of the world. One 1986 textbook describes the Western tradition as "sharply selfcontained and surprisingly immune to outside influences. ${ }^{6}{ }^{\text {This }}$ isolating view is perpetuated whenever history is taught as a linear chronological narrative from ancient times to the present. 


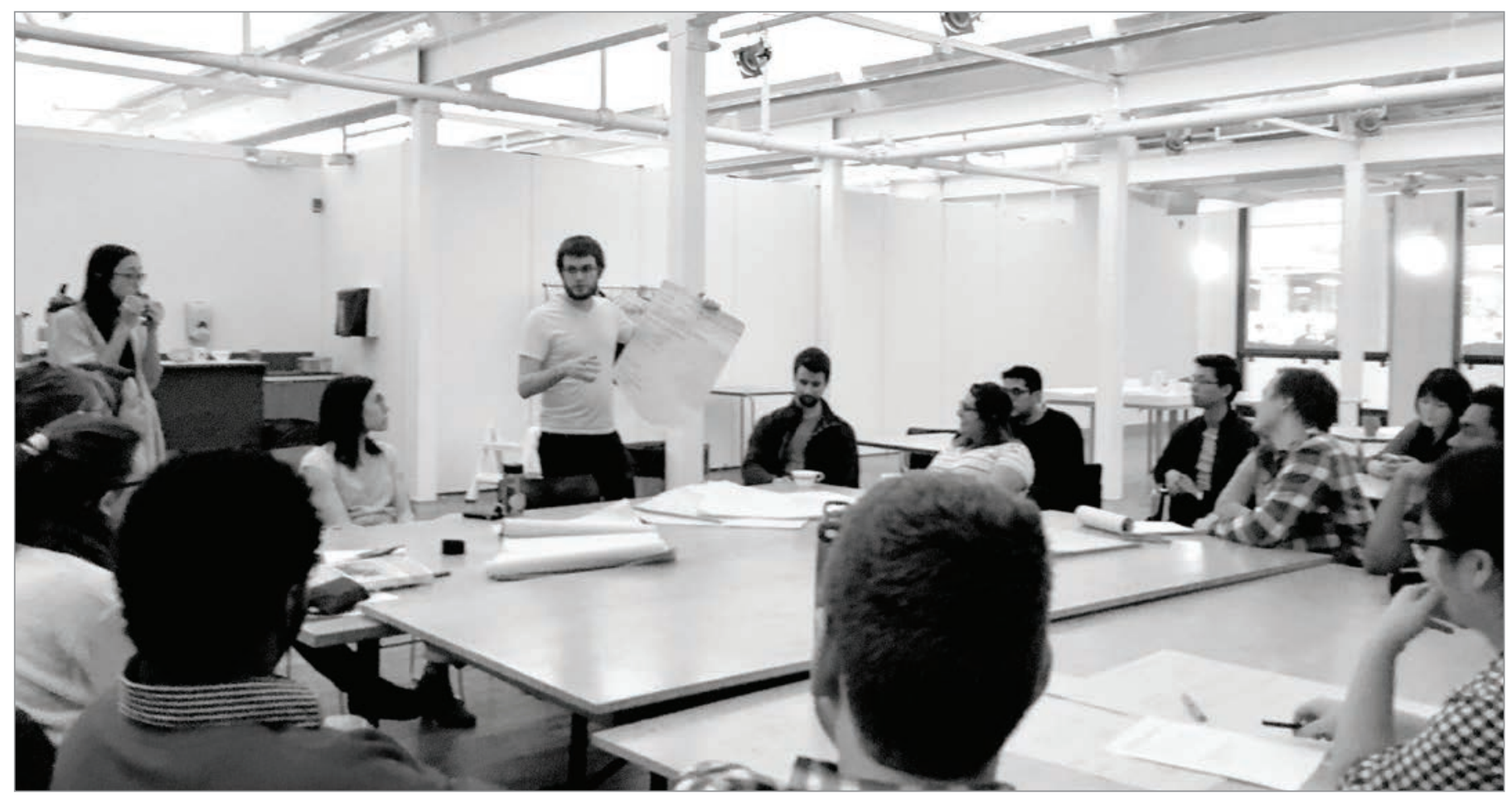

FIG. 4. GROUPS PRESENTING THEIR PROPOSED COURSE SYLLABI DURING THE "EXPANSION PACK" SYLLABI WORKSHOP ON MARCH 22, 2017. | AMINA LALOR.

In the previously mentioned study by Gürel and Anthony, their survey of textbooks assigned at leading American architectural schools revealed that the contributions of women and minorities were minimally included. ${ }^{7}$ Despite the growing body of scholarship looking at non-Western, minority, and women architects, schools and textbooks lag behind in covering their contributions.

Compounding the problem, in recent years, the $J A E$ has almost ceased to publish articles tackling the questions of diversity in architectural curricula, among students, and in the profession. There seems to be a gap in the conversation.

In our research, we looked through the archives of JAE issues from 1990 to the present day. We looked specifically at articles covering any or all of the following three main topics: diversity in the curriculum, diversity and gender balance among students, and diversity and gender in the profession. The total number of articles on these topics for fiveyear periods between 1991 and 2015 are as follows: 1991-1995: 16; 1996-2000: 14; 2001-2005: 20; 2006-2010: 4; 2011-2015: 5.

To be clear, there continue to be many articles in the journal that cover nonWestern content. However, there has been a steep drop since 2005 in the discourse specifically around diversity in curricula, among students, and in the profession. Since 2015, there has only been one article covering these topics. We cannot accurately speculate on why this might be. As we will discuss through our survey of the curricula at various Canadian schools, however, the task of promoting inclusivity is far from done.
Canadian schools of architecture have inherited the use of the Western Canon because they are working within a settlercolonial framework. We must understand that deciding to continue teaching a Eurocentric history is not a neutral choice: it means teaching a history that "comes from away" - teaching by default as settlers, importing a history from somewhere else, displacing the stories that originated on this particular ground. Our relationship to this place and its past is complex. To teach architectural history in Canada without acknowledging this complexity is to ground students in a context that is not here, and to re-entrench a settlercolonialist mindset by unquestioningly overlaying that other context on this land.

Bozdogan summarizes the challenge as follows: "How can we begin to incorporate the insights of postcolonial theories and revisionist histories into the 


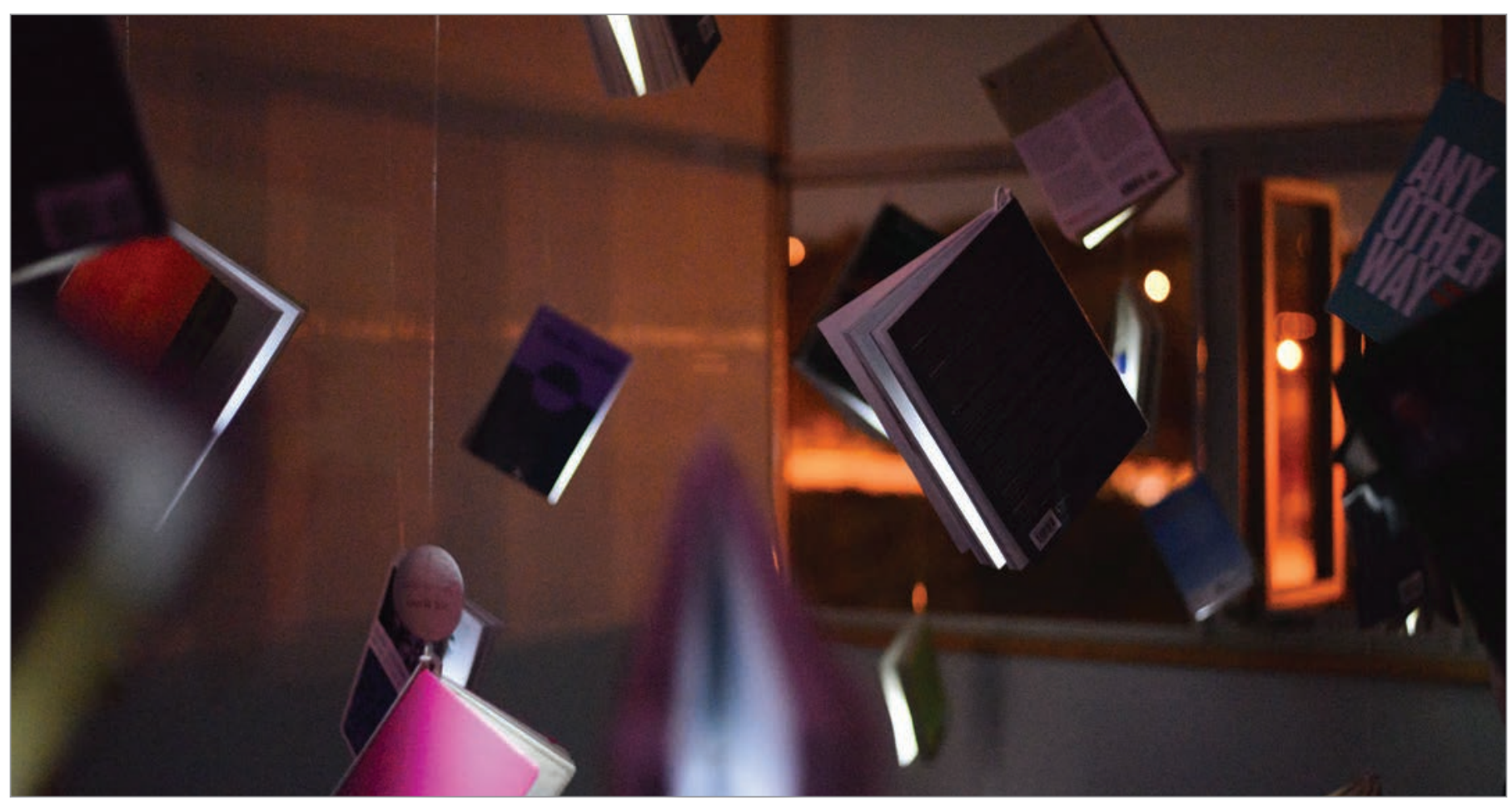

FIG. 5. "WHAT BINDS US" INSTALLATION AT THE ONTARIO ASSOCIATION OF ARCHITECTS MOVE PARTY ON SEPTEMBER 15, 2017. | AMINA LALOR.

education of the architect? How can we expose the biases and exclusions of the Western canon without discarding it altogether?"8 She goes on to propose, as a starting point, to recognize that we are not trying to create a new canon out of the marginalia-the goal is not a new, alternate orthodoxy. The point is to show the interconnectedness of ideas, events, and voices. ${ }^{9}$

The aim is not simply the inclusion of other voices within the hierarchy, but exposing the hierarchy itself. ${ }^{10} \mathrm{~A}$ revised framework is needed, in which we can study the contributions of women and minority architects, clients, and critics. These works should be recognized as worthy of full engagement and critique, not just put on a pedestal as token successes. Conversely, as Bozdogan points out, "exposing the euro-centrism, orientalism, and colonialism of the canon does not diminish the value of the canonic works." 11 We can critique the politics surrounding a work of architecture, and still appreciate the formal power of the work itself.

How do we dismantle the "Grand Narrative," with its gravitational centre fixed on the Western Canon? We are not talking about going from a geocentric to a heliocentric universe, where the earth spins around the sun instead of the sun around the earth. The world of cultures is not like that. It is more like an asteroid field, with each distinct body exerting gravitational force on the others, sometimes colliding, fragmenting, intermingling, but existing together and affecting each other (fig. 1). Or, to use the Deleuzian metaphor, the world of cultures is more like a rhizome than a tree.

\section{CURRICULUM SURVEY}

To find out if the complexity mentioned above has been acknowledged and taught in Canadian architecture schools (fig. 2), we conducted a preliminary survey of their curricula. ${ }^{12}$ We hoped to identify both strengths and gaps in their content through assessing each curriculum's exposure to cultural courses, the coverage of non-Western material, the range of faculty expertise, and the access and exposure of students to diverse content.

We started on familiar ground. At Waterloo, the Cultural History/Theory stream is a major component of the undergraduate curriculum, with seven required courses and three designated electives. All of these work primarily or exclusively with Western content. Some reading lists and lectures are beginning to include non-Western subjects, ${ }^{13}$ 
but so far, this has only happened as a slight "expansion" of the canon and does not question the overall structure. No courses, with the exception of occasional electives, ${ }^{14}$ currently deal with Canada's Indigenous heritage. Some studio courses have begun to expand the global reach of their precedent lists. ${ }^{15}$ Electives focused on international urban expansion ${ }^{16}$ and the Russian avant-garde ${ }^{17}$ are examples of courses broadening the picture.

Next, we reached out to the eleven other Canadian schools of architecture. ${ }^{18} \mathrm{We}$ asked for syllabi, curriculum outlines, and course descriptions. We supplemented information we were sent with material gathered on the schools' websites.

There is a wide spectrum of approaches to the amount of historical, cultural, and theoretical content covered at different schools, ranging from the minimum twenty-four semester hours ${ }^{19}$ (twelve in history of architecture, six in human behaviour, and six in humanities and/or social sciences) ${ }^{20}$ required by the Canadian Architectural Certification Board (CACB) for accreditation, ${ }^{21}$ to Waterloo's prescription of seven courses, well beyond the minimum required semester hours. Most schools supplement their prescribed cultural, theoretical, and historical courses with a requirement for a mandated number of credits in electives covering these topics. On the whole, however, most curricula appear to stay within the Western tradition.

With the exception of Laurentian University, no curriculum prescribes core courses on Indigenous content or devotes core courses to non-Western theory and history. Any exposure outside of this Western default is typically supplied through additional electives, or independent study courses, if at all. At some schools, required electives are broken into topical categories from which students must choose a minimum number in each group. A history and theory category is one of the most common, appearing in the programs at the universities of Toronto, McGill, Dalhousie, Carleton, Laval, and Université de Montréal. Some schools require a minimum number of courses to be taken outside of the architecture faculty, for exposure to more humanities-based topics. ${ }^{22}$

The lack of non-Western representation also manifests itself in how architecture is approached pedagogically. In our experience with the curriculum at Waterloo Architecture, non-Western design approaches are typically summarized in vernacular case studies of the past. Other worldviews on the built environment are neglected in precedents selected for design studio courses. The non-Western content gets presented as pieces in the museum of architectural history, frozen in time, and not accessible in modern design practice. In international development courses available in schools such as McGill, Dalhousie, and the University of Toronto, Western approaches and sensibilities are applied with the intention of "betterment" in the local communities in question. International experience courses taking the form of full study terms ${ }^{23}$ or field trips abroad often remain firmly seated in Western contexts. ${ }^{24}$

Challenges also arise from limitations in faculty expertise and from a lack of diverse tenured faculty members. Some schools combat this by having multiple professors collaborate to teach introductory courses. ${ }^{25}$ Critically positioned courses such as "Uncharted Territories: Iran," offered by the University of Toronto's Daniels Faculty in winter 2017, are few and far between, and are prone to becoming fairly niche classes. Kathryn H. Anthony comments:
When such courses are offered in schools of architecture, they are usually smallscale seminars and electives. As one might imagine, students who enroll in such classes are already favourably predisposed to the material, and the instructor is "preaching to the choir." And, unfortunately, most students graduate without any exposure at all to diversity issues... ${ }^{26}$

\section{COMMUNITY ENGAGEMENT}

Coming out of Waterloo's culturallyfocused but Eurocentric undergraduate program, we each struggled to find critical non-Western discourse addressing our master's thesis topics. Frustrated, we found ourselves confiding in each other and so, Treaty Lands, Global Stories started as an informal conversation over burgers, fries, and cider at a local Cambridge pub in the fall of 2016. Determined to encourage diversity within our curriculum, we agreed that it was time to formalize the conversations we had had at student gatherings for far too long. This was an attempt to influence tangible change. Our intention, from the start, has been to make our curriculum, already rich with cultural content, more inclusive, responsive to our local context, and representative of our student body.

Thus far, our engagement with the school community has taken form in three ways: sharing stories through personal essays on our student website, making space for conversation, and advocating for change in our curriculum.

First, we launched our initiative by publishing a personal essay called Position, Identity, Story: Help! I'm Lost in the Curriculum, ${ }^{27}$ covering Paniz Moayeri's personal experiences as an immigrant navigating architecture school in Canada. The response from students, alumni, and 


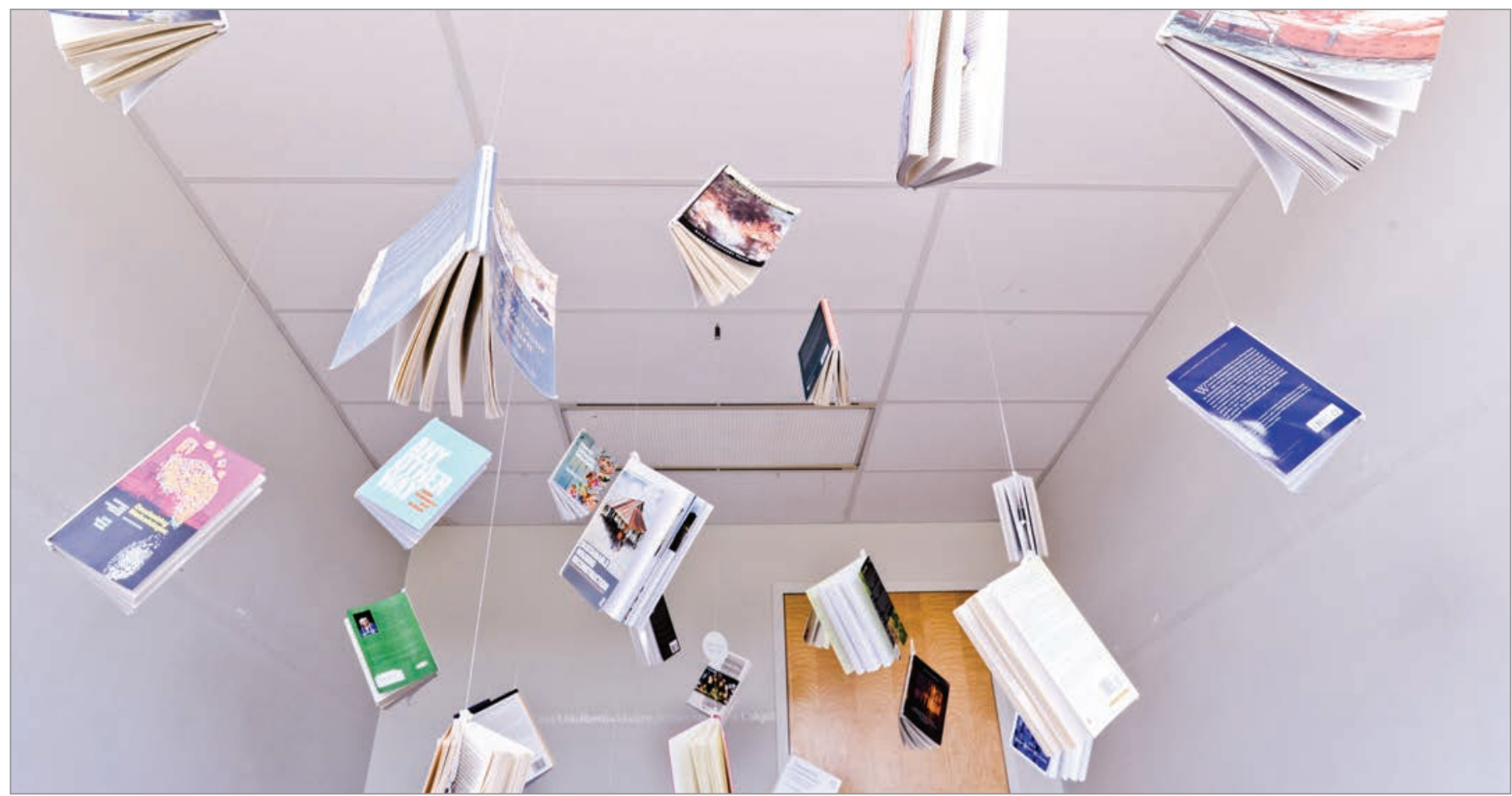

FIG. 6. "WHAT BINDS US" INSTALLATION IN DAYLIGHT. | AMINA LALOR.

faculty was overwhelming. We received emails, Facebook messages, and were stopped in the hallways of Waterloo Architecture by professors and schoolmates who made comments such as the following:

I actually took a whole year off for precisely this issue! .. . [l will be] documenting and researching my own cultural history in China . . . It scared me that my development as a person and the ways I was being moulded to think were so entirely based on the writings of "old white men through the ages." (Undergraduate student at Waterloo]

As a non-white person of no particular faith, I felt a bit alienated and had lots of questions. How rich was this program if it excluded most of the world? (Recent M.Arch. graduate at Waterloo]
The essay also inspired an informal lecture presented by associate professor Val Rynnimeri on his own experiences as a child immigrant to Canada. We followed up with an article entitled "History Here is the Story of Somewhere Else." 28 The collection of articles on the student-run "Bridge" website is ongoing. ${ }^{29}$

Our next area of focus has been organizing events to make space for conversation. Our first event, held in the fall of 2016, consisted of a wide-ranging discussion inviting students and alumni to share their thoughts on inclusivity within Waterloo Architecture's curriculum. Later, we collaborated with the school in presenting the winter 2017 Arriscraft lecture series, entitled "Building on Differences." Before each lecture, we held informal round table conversations with our guest speakers, open to all interested faculty and students, centred on ideas of inclusivity. In the same term, "Expansion Pack" was a workshop organized in collaboration with assistant professor Jane Hutton. Students were given the chance to imagine what course syllabi that tackle difficult questions might look like (figs. 3-4).

In September 2017, we represented Waterloo Architecture at the Ontario Association of Architects (OAA) // MOVE Party, with an installation called "What Binds Us." (figs. 5-6) This project aimed to challenge the canon by displaying thirty books that cover topics often overlooked in formal architectural education. ${ }^{30}$ These books carry content we believe will enrich the education of future architects. Selected on the basis of suggestions from the Waterloo Architecture community and beyond, and purchased using the onethousand-dollar installation budget, the 


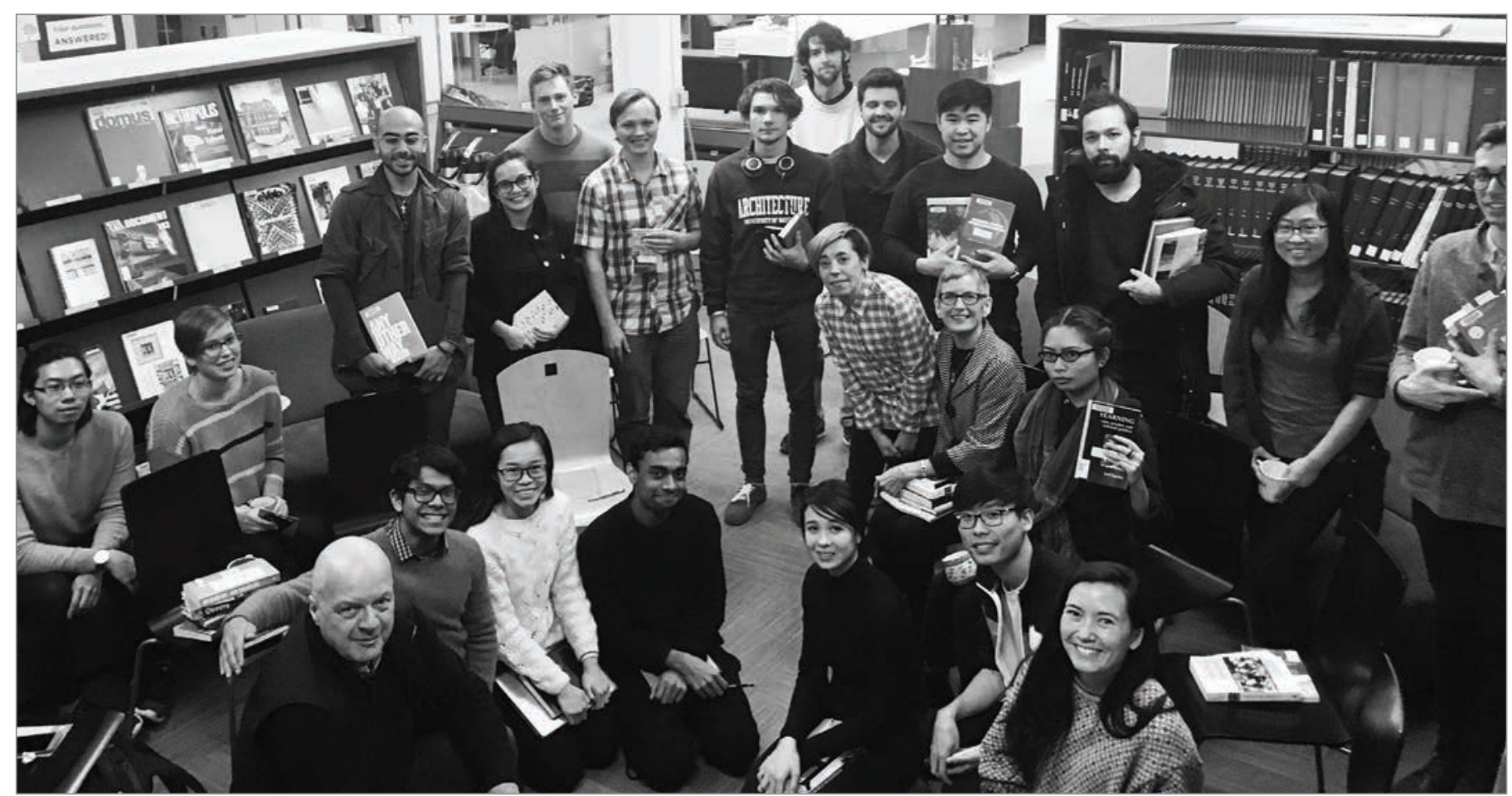

FIG. 7. A GATHERING OF STUDENTS, STAFF, AND FACULTY AT WATERLOO ARCHITECTURE TO DISCUSS THE THIRTY BOOKS INCLUDED IN THE "WHAT BINDS US" INSTALLATION ON NOVEMBER 9, 2017. | PANIZ MOAYERI.

thirty books have since been donated to the Musagetes Architecture Library at the University of Waterloo. "What Binds Us" is an ongoing project. We continue to encourage additions to our alternative reading list through an open-source document. ${ }^{31}$ Further, we continue to host conversations, events, and film screenings centred on the themes highlighted by these titles (fig. 7). ${ }^{32}$

Our final area of focus has been advocating for change in our school's curriculum. We summarized student feedback and ideas in a draft report that we have reviewed with Waterloo Architecture's director, Anne Bordeleau.

\section{ASKING THE RIGHT QUESTIONS}

We started with the question: "What does an inclusive curriculum look like?" We do not know the answer to that question. No one does, because there is not just one answer. There will never be a perfectly inclusive curriculum, because there will never be an exhaustive curriculum. Teaching involves selecting, filtering, interpreting. But how do you decide what to bring in and what to leave out? How do you frame it? And who teaches? Those three questions-about content, delivery, and faculty-will help structure this last section, in which we acknowledge how much we have yet to learn, and how much there is for all of us, together, to do.

What is visible in the schools, and what we have experienced at Waterloo, is the durability of the canon. What do we do about it? One idea, already being implemented in several cultural courses at Waterloo, is to make small modifications to expand scope-for example, adding a book on Islamic architecture to the reading list for the Early Middle Ages. This is a short-term fix, but starting with at least some inclusion might provoke questions and encourage further change. Is it possible to have a gradual process beginning with an exclusive Canon, then expanding it, and then questioning the Canon altogether? Or do we need a revolution to explode the canon from the start?

If we can imagine rebuilding from the ground up, what kind of history would we want to teach? It seems important to emphasize the dynamism and pluralism of cultures-but which cultures? How do we choose? Do we take a survey of the demographics of our school, or of the province, and write courses based on that? Do we try to give a brief overview of just about everything? Or do we dive deep into specific topics? Maybe it is less about comprehensiveness of content. Maybe it is more about equipping students to work within a multicultural but 
settler-colonial society, a country with a dark and complex heritage. It may be possible for each school to have an entirely different, equally valid, equally problematic approach.

The one imperative is the inclusion of Indigenous culture and history. In 2016, Waterloo Architecture began to make land acknowledgements at the beginning of lectures and all-school meetings. This, too, is a tiny, and even potentially problematic, first step. But imagine if each school went beyond this, and educated its students about the significance of the ground they walk on every day? What opportunities might open up for each school to connect more fully with its location and context?

Each school is unique. Each school has different strengths, different areas of focus, and different local contexts. How might a school's particular identity suggest unique ways of approaching inclusivity? Different worldviews can massively affect the way we operate in areas like building science, or sustainability, or fabrication. How might exposure to Indigenous perspectives on issues like land, or permanence and durability, change our ethos as builders and makers?

With that in mind, who decides which stories to tell? And who tells them? The life experiences of professors inevitably affect what they choose to research, how they look at the world, and the way they teach. But with a limited number of faculty at each school, and new hires happening rarely, what can we do in the meantime? Sessional faculty can bring more diversity and expertise. Other short-term strategies might include inviting diverse guest speakers to participate within courses and lecture series, creating more interdisciplinary collaborations, or asking multiple professors to teach one course. It may also be helpful to compile a list of contacts for faculty in other disciplines or schools who can help with graduate student research. In the long term, however, it seems like one of the most transformative things any school can do is to hire diverse faculty, with diverse areas of expertise.

What about the delivery of content-the way courses are laid out, the way curricula are structured? In the short term, adding diverse electives seems like a good strategy for opening up the curriculum. Giving students choices to help curate their own education is also a worthy goal. ${ }^{33}$ But in the long term, if the core courses remain white and Western, it perpetuates a situation of dangerous imbalance. This situation is described by our Waterloo Architecture colleague Samiha Meem, in her manifesto The Anti-White Space: "White is the default. White is the normal. All outside it is questionable, more thoroughly vetted, and suppressed. Using their system, architecture exercises its white saviour complex-seeing the lives of minorities as design problems..." ${ }^{34}$

Students of colour not only lack role models and representation, but are also made to feel that the world of design does not belong to them. How do we bring people of colour into the core of the curriculum, instead of leaving them on the periphery?

Curricula are living, breathing creatures that will forever need tending to. How can we make reaching for inclusiveness into an active, ongoing conversation? How do we keep challenging our norms? One way might be to support and strengthen learning beyond class lectures. How can this take shape? How might a curriculum respond to the ideas that are generated?
We will continue to advocate for change within our school and encourage the conversation to grow. But the question remains: what does an inclusive architecture curriculum look like, in this country of treaty lands and global stories?

\section{NOTES}

1. We would like to thank the University of Waterloo School of Architecture's O'Donovan director, Anne Bordeleau, and assistant professor, Jane Hutton, for their invaluable help, guidance, and support in this work.

2. Said, Edward W., 1979, Orientalism, New York, Vintage Books.

3. Oxford English Dictionary, [http://www.oed. com/], accessed April 18, 2017

4. Gürel, Meltem Ö. and Kathryn H. Anthony, 2006, "The Canon and the Void," Journal of Architectural Education, vol. 59, no. 3, p. 66, [https://www.tandfonline.com/doi/ abs/10.1111/j.1531-314X.2006.00036.x], accessed April 13, 2017.

5. Bozdogan, Sibel, 1999, "Architectural History in Professional Education: Reflections on Postcolonial Challenges to the Modern Survey," Journal of Architectural Education, vol. 52, no. 4, p. 209, [https://www.tandfonline.com/doi/abs/10.1111/j.1531-314X.1999. tb00273.x], accessed April 19, 2017.

6. Trachtenberg, Marvin and Isabelle Hyman, 2002 [2 ${ }^{\text {nd }}$ ed.], Architecture: From Prehistory to Postmodernity, New York, H.N. Abrams.

7. Gürel and Anthony, "The Canon and the Void," op. cit.

8. Bozdogan, "Architectural History in Professional Education," p. 208.

9. Ibid.

10. Id., p. 209.

11. Id., p. 212.

12. Our literature review and curriculum survey were conducted in 2017. Some curriculum material may have changed or been updated since then.

13. An example is the inclusion of Mohammad Hamdouni Alami's Art and Architecture in the Islamic Tradition: Aesthetics, Politics and Desire in Early Islam (London, UK, I.B. Tauris) to the ARCH 143 reading list. As well, buildings from outside the Western canon were 
included in the architectural history portion of ARCH 246 in fall 2017. There is no guarantee, however, that these small changes will be permanently applied within these courses.

14. Examples include William Woodworth's "Twelve Architectures" elective course and John McMinn and Paul Dowling's design-build elective studios offered in winter and fall 2017 in collaboration with Kayanase on Six Nations. (Kayanase is an ecological restoration and native plant and seed business based on the Six Nations Reserve near Brantford, Ontario: [https://kayanasegreenhouse.weebly.com/].)

15. John McMinn's ARCH 392 in the winter of 2017 is an example.

16. Spring 2017 ARCH 684_001, "Spatial Topologies of Globalized Neoliberal Urbanization," taught by Adrian Blackwell.

17. ARCH 684, "Russian Avant-garde Architectural Theory," taught by Elizabeth English.

18. Ten of which are accredited. Laurentian University's McEwen School of Architecture will be able to seek CACB assessment following the graduation of its first M.Arch. class.

19. Examples include the universities of Manitoba and Toronto.

20. Cultural content and perspectives to be taught are not specified.

21. "A semester hour is equivalent to 1 hour of $C A C B$ approved lecture or 2 hours of $C A C B$ approved laboratory/studio instruction per week for the duration of the semester or term. For programs that operate on a quarter system, 1.5 quarter hours are equivalent to 1 semester hour." Canadian Architectural Certification Board, 2010, Conditions and Procedures for the Certification of Educational Qualifications: Required for Admission (Registration or Licensing) to the Architectural Licensing Authorities in Canada, Ottawa, ON, p. 810, [http://cacb.ca/en/home/] and [http:// cacb.ca/wp-content/uploads/pdf/CACBCCCA Candian Education Standard.pdf], accessed May 8, 2017.

22. Issues of indigeneity, gender, and minority representation all intersect, and are shared between architecture and other fields of study. As such, more holistically intersectional approaches in teaching architecture may help with the inclusion of underrepresented content. One method used in an attempt to achieve this inclusion is mandating a certain number of courses to be taken outside of faculties of architecture. Ryerson, McGill, and
Laurentian all set minimum requirements for a number of humanities or arts and sciences courses to be taken from other faculties in their undergraduate programs. This already happens by default in programs such as the University of British Columbia's Bachelor of Environmental Design and Dalhousie University's Bachelor of Environmental Design Studies, where the first two years of study are done outside of architecture schools as part of general foundation years. The majority of the remaining architecture programs (not mentioned above) tend to be graduate programs geared toward individuals with diverse undergraduate backgrounds.

23. Examples include University of Calgary's study term in Barcelona and Waterloo Architecture's Rome program.

24. Exceptions at Waterloo include Tammy Gaber's class field trip to Turkey in winter 2013 for her Islamic architecture elective, as well as Lola Sheppard's class trips to places like Greenland and Nunavut. Elsewhere, exceptions may include McGill University's Israel and China studios, or Université Laval's courses in Northern Indigenous communities.

25. Most schools of architecture have an introduction to design/architecture in the first term of their programs and a research methodologies course in their graduate programs. Both of these courses are crucial in setting the stage for the students' approach to architecture and research. Representing a one-dimensional definition of architecture in both cases is a missed opportunity. To combat this and to include some nuance, both the University of Waterloo and Laurentian University have incorporated the use of multiple faculty and guest lecturers in these kinds of courses to show a more diverse view of the discipline. Since fall 2016 at Waterloo, the mandatory "Research Methodologies" course in the first term of the graduate program (ARCH 610) uses guest lecturers (some even from other faculties) with different research topics and methodological approaches.

26. Anthony, Kathryn H., 2017, "Designing for Diversity: Implications for Architectural Education in the Twenty-first Century," Journal of Architectural Education, vol. 55, no. 4, p. 263, [https://www.tandfonline. com/doi/abs/10.1162/104648802753657969], accessed April 19, 2017. Examples of this pattern at Waterloo include William Woodworth's former course, "Twelve Architecture," and Tammy Gaber's Islamic architecture elective in the winter of 2013.
27. Moayeri, Paniz, 2017, Help! I'm Lost in the Curriculum, Cambridge, ON, Bridge Centre for Architecture + Design, [http://waterlooarchitecture.com/bridge/blog/2016/11/05/positionidentity-story-help-im-lost-curriculum/], last access April 2018.

28. Ganton, Samuel, 2017, "History Here Is The Story of Somewhere Else," Cambridge, ON, Bridge Centre for Architecture + Design, [http://waterlooarchitecture.com/bridge/ blog/2017/01/16/history-here-is-story-ofsomewhere-else/], last access April 2018.

29. See: [http://waterlooarchitecture.com/bridge/ cat/articles/treaty-lands-global-stories/], last access April 2018.

30. The thirty books that were included in our installation are listed below. While our intention was to select titles with as broad a range of perspectives as possible, we understood that it would not be possible to cover all facets of inclusion and we acknowledge that the majority of selected authors write in English, with two titles translated from French:

- Allen, Brian T. and Holly Edwards, 2000, Noble Dreams, Wicked Pleasures: Orientalism in America, 1870-1930.

- Alsayyad, Nezar, 2001, Consuming Tradition, Manufacturing Heritage: Global Norms and Urban Forms in the Age of Tourism.

- Bouthillette, Anne Marie, Yolanda Retter, and Gordon Brent Ingram, 1997, Queers in Space: Communities, Public Places, Sites of Resistance.

- Brand, Dionne, 2001, A Map to the Door of No Return.

- Braziel, Jana Evans and Anita Mannur, 2003, Theorizing Diaspora: A Reader.

- Chamberlin, J. Edward, 2003, If This Is Your Land, Where Are Your Stories? Finding Common Ground.

- Charlesworth, Esther and Ifekhar Ahmed, 2015, Sustainable Housing Reconstruction: Designing Resilient Housing After Disasters.

- Coulthard, Glen Sean, 2014, Red Skin, White Masks: Rejecting the Colonial Politics of Recognition.

- Crawford, Lucas, 2015, Transgender Architectonics: The Shape of Change in Modernist Space.

- Fanon, Frantz, 1963, The Wretched of the Earth. 
- Gofman, Erving, 1961, Asylums: Essays on the Condition of the Social Situation of Mental Patients and Other Inmates.

- Hill, Susan M., 2010, The Clay We Are Made of: Haudenosaunee Land Tenure on the Grand River.

- hooks, bell, 1990, Yearning: Race, Gender, and Cultural Politics.

- Lorinc, John, Jane Farrow, Stephanie Chambers, Maureen FitzGerald, Tim McCaskell, Rebecka Sheffield, Tatum Taylor, Rahim Thawer, and Ed Jackson, 2017, Any Other Way: How Toronto Got Queer.

- Lu, Duanfang, 2010, Third World Modernism: Architecture, Development and Identity.

- Massey, Doreen, 1994, Space, Place, and Gender.

- Mbembe, Achille, 2001, On the Postcolony.

- Porter, Tom E., 2008, And Grandma Said... Iroquois Teachings.

- Regan, Paulette, Unsettling the Settler Within: Indian Residential Schools, Truth Telling, and Reconciliation in Canada.

- Rizvi, Kishwar, 2015, The Transnational Mosque: Architecture and Historical Memory in the Contemporary Middle East.

- Said, Edward W., 1978, Orientalism.

- Sanford, Jon A., 2012, Universal Design as a Rehabilitation Strategy: Design for the Ages.

- Sedgwick, Eve Kosofsky, 1990, Epistemology of the Closet.

- Simone, Abdou Maliq and Edgar Pieterse, 2017, New Urban Worlds: Inhabiting Dissonant Times.

- Smith, Linda Tuhiwai, 1999, Decolonizing Methodologies: Research and Indigenous Peoples.

- Tsing, Anna, 2005, Friction.

- Walia, Harsha, 2013, Undoing Border Imperialism.

- Watt-Cloutier, Sheila, 2015, The Right To Be Cold: One Woman's Story of Protecting Her Culture, the Arctic and the Whole Planet.

- Weizman, Eyal, 2011, The Least of All Possible Evils: Humanitarian Violence from Arendt to Gaza.

- Woods, Clyde Adrian and Katherine McKittric, 2007, Black Geographies and the Politics of Place.

31. To add to the open-source document, visit: [https://docs.google.com/ spreadsheets/d/11jTZJu3KF-mqjZBSoAchjaq7VBb5-T5cDzSZ9Qz6cj8/ edit?usp=sharing].
32. The topics of these conversations range widely from post-colonial theory, to indigenous issues, to ideas of safe queer space and gendered architecture, and beyond.

33. As previously mentioned, it is impossible to be all-inclusive in the material covered. Electives and independent study courses can open up the horizons. Many schools offer specializations through degree options or streams: Ryerson, Carlton, and Université Laval all allow for this in their undergraduate programs. This method creates multiple parallel curricula with varying degrees of overlap in the core courses. The role of independent study or reading elective courses also contributes to choice. Many schools have versions of these studentdirected syllabi. This is a clear way to ensure students can pursue topics they are interested in, especially at higher levels of education as they conduct thesis research. Adding broader research options within courses, enlisting students to help gain and share expertise in areas that are unfamiliar ground for their professors, is another strategy that can be implemented. It must be understood that these models are not to replace core syllabus material but are ways for supplementing the curriculum if a student needs or wants to delve into specific topics. The faculties' role remains their guidance of students in approaching the material with a critical eye, something that may be less possible in larger-scale survey courses with diverse content.

34. Meem, Samiha, 2017, The Anti-White Space: An Architectural Manifesto, Toronto, ON, Art Metropole, p. 36-42. 